\title{
Infectious Diseases in Children
}

\author{
Ruba M. Jaber, Basmah M. Alnshash, and Nuha W. Qasem
}

\section{Contents}

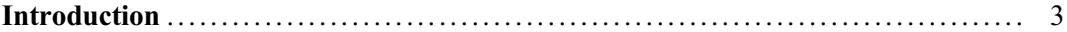

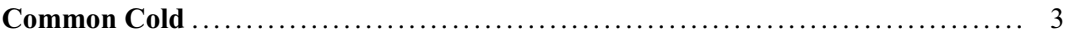

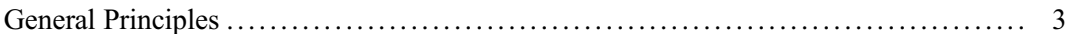

Approach to the Patient Diagnosis, History, and Physical Examination .............. 3

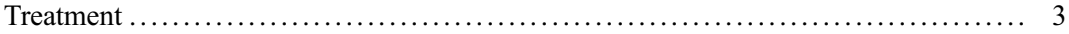

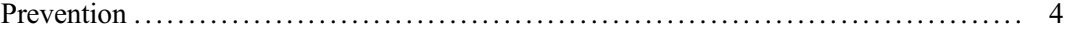

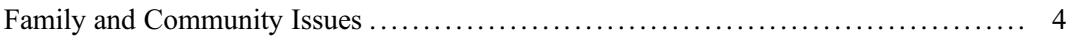

Common Pediatric Viral Exanthems ....................................... 4

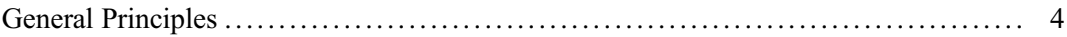

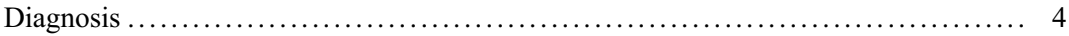

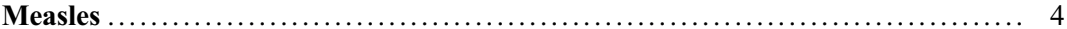

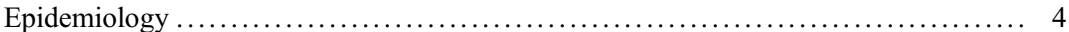

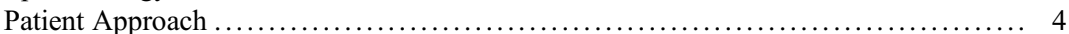

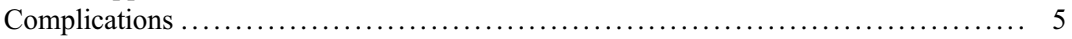

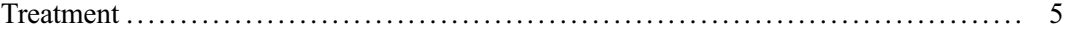

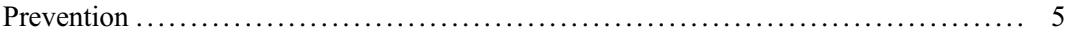

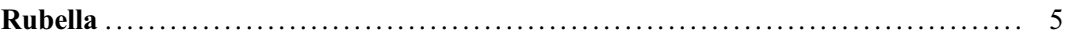

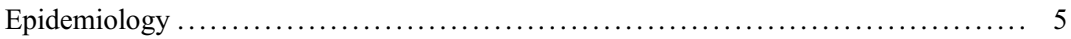

Patient Approach ................................................... 5

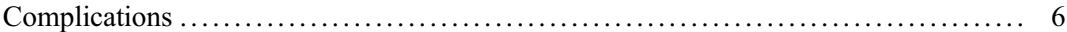

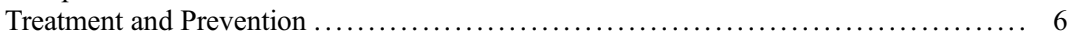

R. M. Jaber $(\bowtie)$

School of Medicine, University of Jordan, Amman, Jordan e-mail: r.jaber@ju.edu.jo; dr.jaber_ruba@ymail.com

B. M. Alnshash

School of Medicine, University of Jordan, Jordan

University Hospital, Amman, Jordan

e-mail: basmahalnashash@yahoo.com

N. W. Qasem

School of Medicine, Hashemite University, Zarqa, Jordan

e-mail: n.qasem82@gmail.com 


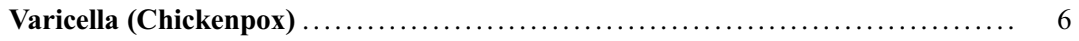

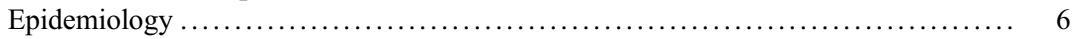

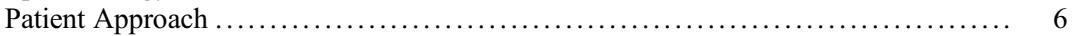

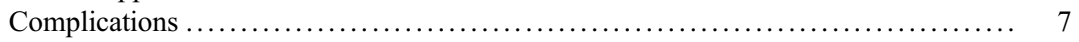

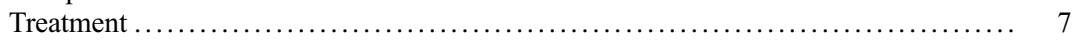

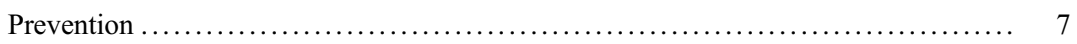

Roseola Infantum (Exanthema Subitum or Sixth Disease) ................... 7

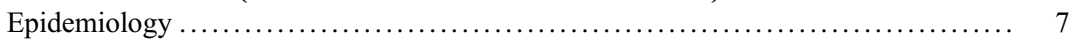

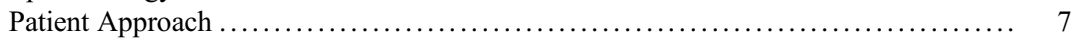

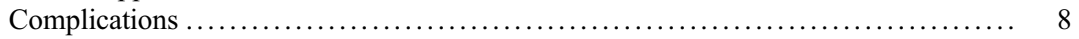

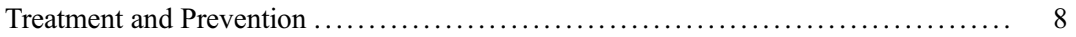

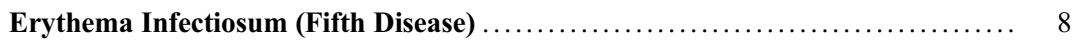

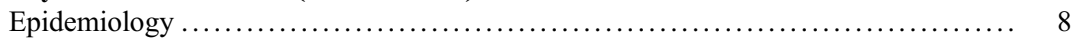

Patient Approach .................................................. 8

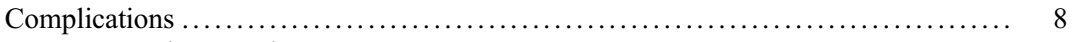

Treatment and Prevention ........................................... 9

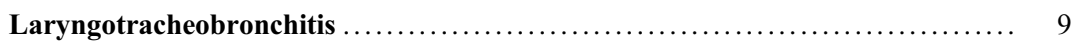

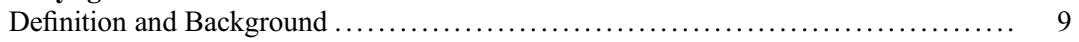

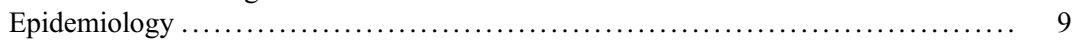

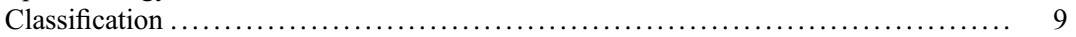

Patient Approach .................................................... 9

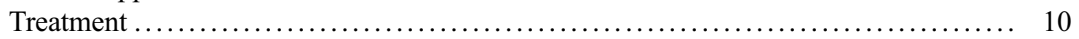

Epiglottitis . . . . . . . . . . . .

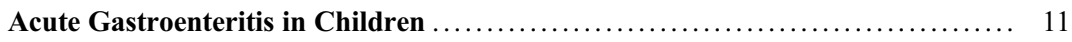

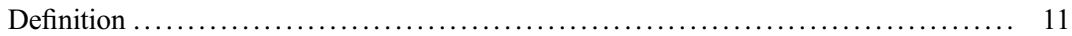

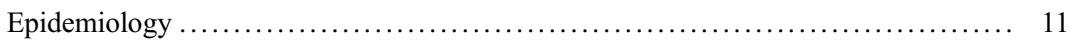

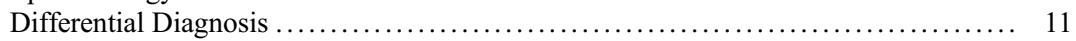

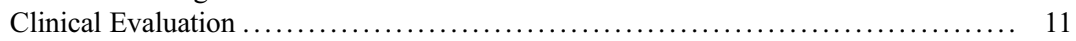

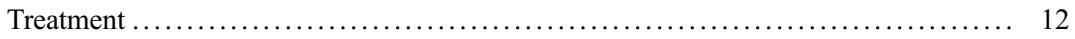

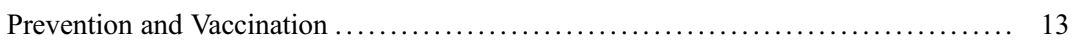

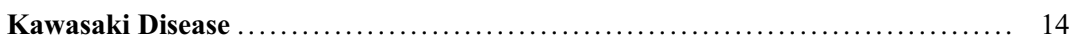

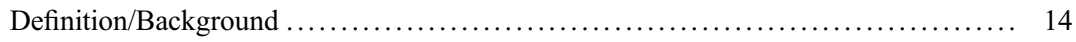

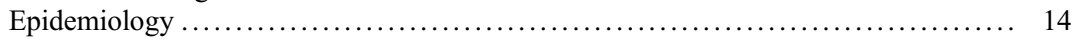

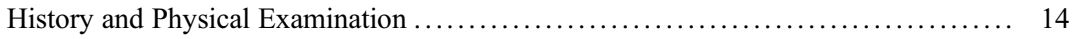

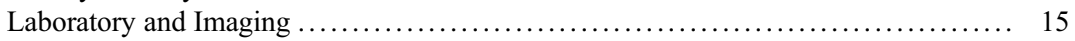

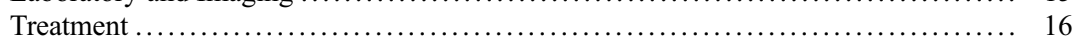

Medications Immunizations and Chemoprophylaxis, Referrals, and Counseling ...... 16

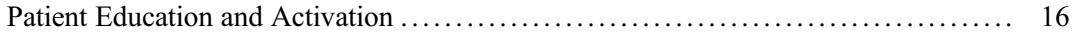

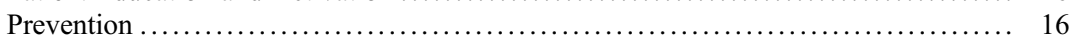

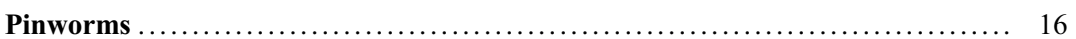

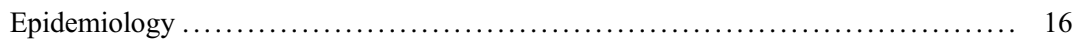

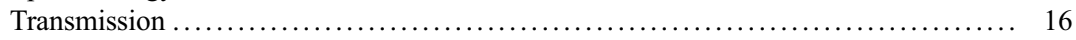

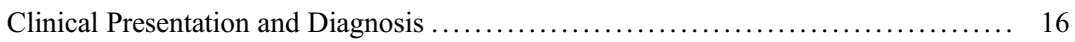

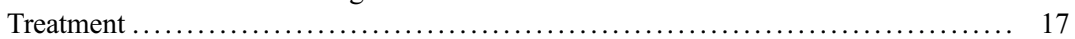

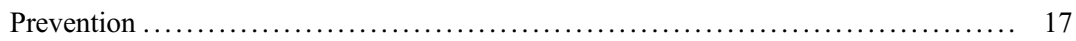

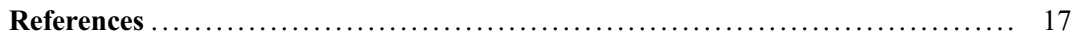




\section{Introduction}

Infectious diseases are one of the most frequent reasons for pediatric consultations. Although mortality and morbidity from infectious diseases have dramatically declined in recent years, infections among children remain important.

Like many other diseases in children, the complications of the disease such as dehydration might be the primary focus of management rather than treating the causative agent, as many infectious diseases in children are self-limiting.

This chapter will discuss some of the more prevalent infectious diseases in children in addition to some that are less common but should not be missed.

\section{Common Cold}

\section{General Principles}

\section{Definition/Background}

The common cold is an acute, self-limiting viral infection of the upper respiratory tract characterized by variable degrees of sneezing, nasal congestion and rhinorrhea, sore throat, cough, low grade fever, headache, and malaise [1].

\section{Epidemiology}

The common cold is the most common infectious disease among children. A healthy child may develop upper respiratory tract infections (URTI) six to eight times per year [2]. Infants and children may experience more prolonged symptoms than adults. Common colds are most commonly caused by rhinovirus, which accounts for about $60 \%$ of infections. Other causes include parainfluenza, respiratory syncytial virus, coronavirus, adenovirus, echovirus, coxsackievirus, and parainfluenza virus [3].

\section{Approach to the Patient Diagnosis, History, and Physical Examination}

The diagnosis of the common cold is based on symptoms. Symptoms usually peak on day $2-3$ of the illness and gradually improve over the next
10-14 days. An associated cough may linger in a minority of children but typically resolves over 3-4 weeks [1, 4]. Fever is uncommon, although temperatures of up to $39^{\circ} \mathrm{C}$ may occur in younger children. A red nose with a profuse nasal discharge may be present. The discharge can be clear and watery or mucopurulent (yellow or green). Purulent secretions are more common after the first few days of illness.

\section{Differential Diagnosis}

The common cold should be distinguished from allergic rhinitis, isolated pharyngitis, acute bronchitis, influenza, bacterial sinusitis, or pertussis [5].

\section{Treatment}

Current guidelines on the treatment and management of respiratory tract infections (RTIs) in children emphasize supportive management. This includes hydration, nasal suction, saline nasal drops, spray, or irrigation. A cool mist humidifier may be helpful. Parents may give acetaminophen to children older than 3 months or ibuprofen to children older than 6 months to treat the discomfort associated with any fever. Over-the counter (OTC) medications such as cough medications or antihistamines are not recommended for young children. As most RTIs are caused by viruses, antibiotics should only be prescribed if an RTI is suspected to be of bacterial origin.

Zinc, vitamin $\mathrm{C}$, and herbal products such as echinacea are advertised to treat or prevent the common cold. There is some evidence that prophylactic use of vitamin C may decrease the duration of the common cold in children. However, with the exception of vitamin $\mathrm{C}$, none of these treatments have been proven to be effective in clinical trials and thus their use is not recommended [6].

Complications of the common cold include acute otitis media, acute bacterial sinusitis, asthma exacerbation, and lower respiratory tract disease. Re-evaluation may be warranted if the symptoms worsen (e.g., difficulty breathing or swallowing, high fever) or exceed the expected duration. 


\section{Immunizations and Chemoprophylaxis}

The Centers for Disease Control and Prevention (CDC) recommends a yearly flu vaccine as the first and most important step in protecting against influenza and its potentially serious complications. All children 6 months and older should receive the influenza vaccine every year before flu activity begins in their community [7].

\section{Prevention}

The best methods for preventing transmission of the common cold are frequent hand washing and avoiding touching one's mouth, nose, and eyes. Most children with colds need not be excluded from out-of-home childcare or school because transmission is likely to have occurred before the child became symptomatic [1].

\section{Family and Community Issues}

The common cold accounts for approximately 22 million missed days of school and 20 million absences from work, including time away from work to care for ill children.

\section{Common Pediatric Viral Exanthems}

\section{General Principles}

\section{Definition}

An exanthem is a term used to describe skin lesions associated with other systemic manifestations like fever. Exanthems can be caused by infections or allergic reactions to medications or to other agents. Viral infections account for the majority of cases of exanthems in children.

\section{Classification}

Pediatric viral exanthems can be classified based on the presentation of the skin lesions, into maculopapular and vesicular rashes. Viral exanthems that manifest with a maculopapular rash include measles, rubella, roseola infantum, and erythema infectiosum. Conversely, varicella and hand-foot-and-mouth disease (HFMD) present with papulovesicular rash.

\section{Diagnosis}

\section{History and Physical Examination}

Differentiation should be based on the morphologic appearance of the lesions, their distribution and order of appearance, their relation to fever, and the presence of other associated physical findings that can be characteristic and sometimes pathognomonic for a specific viral illness. Diagnosis of pediatric viral exanthems is largely based on the clinical presentation and a good history. Laboratory evaluation is usually not necessary.

\section{Measles}

\section{Epidemiology}

Measles is a highly contagious disease caused by a paramyxovirus which carries high risk of serious complications and fatalities. Following the introduction of the measles vaccine in 1963 the disease has dramatically declined. However, provisional data from the World Health Organization (WHO) indicates that during the first 6 months of 2019 there have been more measles cases reported worldwide than in any year since 2006 [8].

\section{Patient Approach}

\section{Clinical Presentation}

Measles virus can be acquired via respiratory droplets from infected individuals. After an incubation period of 1-3 weeks, patients have a two-to-four-day prodromal phase characterized by fever, malaise, cough, coryza, conjunctivitis, and Koplik spots. These spots are pathognomonic for measles infection. They appear as small, grayish white papules in the buccal mucosa opposite to the molar teeth and have been described as "grains of salt on a red background." They can last for 12-72 $\mathrm{h}$ and start to disappear with the onset of 
a skin rash. The maculopapular rash first appears in the preauricular area then spreads centrifugally to the rest of the body. The fever usually persists for 3 days after the onset of rash. After 6-7 days the rash starts to disappear in the same order of its appearance. Infection usually results in lifelong immunity, although in rare cases reinfection may occur and present with modified measles having milder clinical manifestations.

\section{Complications}

Measles infection can be complicated by a decline in T-cell related immune response leading to an increased risk of infections during and shortly after measles infection. Common complications include gastroenteritis, otitis media, pneumonia, and other respiratory complications. Pneumonia is the most common life-threatening complication. Measles infection can also affect the central nervous system, leading to acute encephalitis, acute disseminated encephalomyelitis (ADEM), and subacute sclerosing panencephalitis (SSPE). Acute encephalitis usually occurs within a few days of the appearance of a rash and is directly due to viral infection. Conversely, ADEM is thought to be a postinfectious autoimmune response. It may also be triggered by other infectious agents, but it carries a higher mortality rate when it follows a measles infection.

SSPE manifests 7-10 years after measles infection and is characterized by progressive neurodegenerative changes. It is thought to be caused by persistent measles virus infection within the central nervous system. Measlesrelated complications may occur in up to $30 \%$ of cases in immunocompetent, and more frequently in immunocompromised patients, pregnant women, individuals with vitamin A deficiency, or in individuals younger than 5 years or older than 20 years [9].

\section{Treatment}

In addition to symptomatic treatment, Vitamin $\mathrm{A}$ administration once daily for 2 days reduces mortality and morbidity from measles. This is because vitamin A deficiency contributes to a delayed recovery and the high rate of postmeasles complications. In addition, acute vitamin A deficiency and xerophthalmia may be precipitated by measles infection [9]. Ribavirin may be considered for patients with measles-related pneumonia or patients with severe immunosuppression.

\section{Prevention}

A two-dose live attenuated measles vaccine is recommended as part of the MMR vaccine given after the child's first birthday. In addition, isolation of infected persons immediately upon making the diagnosis, and until 4 days after the onset of rash can help reduce viral transmission.

\section{Rubella}

Rubella is caused by infection by an RNA virus of the Togaviridae family. The infection is also known as "the three-day measles" or "German measles."

\section{Epidemiology}

After introduction of the rubella vaccine, there has been a significant drop in its incidence and complications. Sporadic outbreaks have been reported when vaccination rates lag.

\section{Patient Approach}

\section{Clinical Presentation}

The virus is transmitted via respiratory droplets. After an incubation period of 2-3 weeks, patients start to have mild prodromal symptoms for 1-5 days, such as a sore throat, low-grade fever, myalgias, and symmetrical posterior cervical lymphadenopathy, mainly in the postauricular and occipital regions. Then, a maculopapular skin rash starts to appear on the face and rapidly spreads in a craniocaudal manner. This rash 
typically lasts 3 days (thus the name "three-day measles"). However, nearly $50 \%$ of individuals are asymptomatic during infection. Arthritis or arthralgias occur in up to $70 \%$ of adolescents, particularly females.

\section{Complications}

Complications following rubella infection are infrequent. However, maternal infection during pregnancy can lead to intrauterine fetal death, preterm delivery or congenital rubella syndrome (CRS). The risk of CRS increases if maternal infection occurs early in pregnancy and is less likely if it occurs during the second half of the pregnancy. Infants with CRS can have heart defects, eye defects like congenital cataracts, neurodevelopmental disorders, and bilateral sensorineural hearing impairment.

Encephalitis can rarely follow rubella infection but is more likely to affect adults than young children. Coagulopathy leading to hemorrhagic complications tends to affect infected children more than adults [10].

\section{Treatment and Prevention}

Treatment is largely supportive as the disease usually has a mild course, especially among children. Rubella infection can be prevented by administering a live-attenuated rubella vaccine as part of the MMR vaccine given as two doses. Infected individuals are considered infectious from 7 days before the appearance of a rash to 7 days following its disappearance. Therefore, patients should be isolated for more than a week following the onset of a skin rash.

\section{Varicella (Chickenpox)}

Varicella is caused by a double stranded-DNA neurotropic virus from the Herpesviridae family. Primary infection can be followed by the dormant presence of the virus in the dorsal root ganglia of the spine which can be reactivated later in life with waning of cell-mediated immunity and manifest as a zoster infection (shingles) with its potentially incapacitating postherpetic neuralgia.

\section{Epidemiology}

Varicella occurs worldwide and, in the absence of a vaccination program, affects nearly every person by mid-adulthood. In areas with an implemented varicella vaccine programs, there have been drops in both incidence and complications. Chickenpox is considered highly contagious, with a secondary household attack rates of $>90 \%$ in susceptible individuals.

\section{Patient Approach}

\section{Clinical Presentation}

The virus is acquired either via respiratory droplets or by direct contact with vesicular fluids of an affected individual. After an incubation period of 10-21 days, patients start to manifest mild prodromal symptoms like low-grade fever, malaise, and a sore throat, followed by the appearance of pruritic skin lesions within $24 \mathrm{~h}$. Lesions first appear on the trunk or scalp and then spread centrifugally to the extremities. Mucous membranes in the mouth and conjunctivae can be also involved.

Lesions start as a macule that evolves into a papule and then into a vesicle filled with clear fluid, which eventually crusts. New crops of lesions continue to appear in the next few days. Thus, in the same area you can see the coexistence of papules, vesicles, and crusts at the same time, a finding characteristic of varicella. New vesicle formation generally stops within 4 days, and most lesions have fully crusted by day 6 in normal hosts [11]. After the disappearance of the crusts (usually 1-2 weeks later), they are replaced by hypopigmented macules which persist for some time. 


\section{Complications}

Varicella infection in immunocompetent children is considered to be a mild and self-limiting disease with a rare occurrence of serious complications. However, infants, adults, adolescents, and immunocompromised individuals are more prone to complications. The most common complication of varicella is bacterial superinfection of the lesions with invasive group A streptococcal or staphylococcal infection in the skin and subcutaneous tissue.

Pneumonia can also be a complication of varicella in adults and immunocompromised individuals. Encephalitis, aseptic meningitis, and transverse myelitis are the main neurologic complications of varicella. In addition, Reye syndrome was a complication observed among children who had been given a salicylate as an antipyretic during the infection. However, after cessation of the use of salicylates in children, it is now rarely seen.

If maternal infection occurs during pregnancy, transplacental transmission of the infection can ensue, leading to congenital varicella syndrome. This can result in low birth weight and multiple congenital abnormalities such as skin scarring, limb hypoplasia, eye abnormalities such as optic nerve atrophy and cataracts, microcephaly and mental retardation.

\section{Treatment}

In immunocompetent children, treatment is largely supportive as the infection tends to be self-limited. Acetaminophen is recommended to control fever and calamine lotion or other soothing lotions can be given to control pruritus. However, in adolescents, adults, immunocompromised patients, and children with chronic skin or lung diseases, acyclovir is indicated for 5 days starting within $24 \mathrm{~h}$ of rash onset to decrease the severity of symptoms and the disease duration.

\section{Prevention}

A live-attenuated vaccine for VZV has been available since 1995. It is administered as two doses at 12-15 months and at 5 years as part of the measles, mumps, rubella, and varicella (MMRV) vaccine or as a separate vaccine. Unvaccinated adolescents and adults who have no history of primary infection are advised to receive two doses of the vaccine separated by at least 28 days.

Patients are typically infectious from $48 \mathrm{~h}$ before the appearance of a skin rash until crusting of all the skin lesions, which usually takes place 1 week after the onset of the rash. Therefore, patients should be isolated for at least 1 week following appearance of the exanthem.

\section{Roseola Infantum (Exanthema Subitum or Sixth Disease)}

\section{Epidemiology}

This is a mild self-limiting disease caused by Human Herpes Virus 6 B (HHV6B) and less frequently by HHV6A and HHV7 viruses. It usually affects infants between 6 and 12 months of age, almost $90 \%$ of the cases are children under the age of 2 . The virus is usually transmitted to the infant from a healthy asymptomatic carrier individual [12].

\section{Patient Approach}

\section{Clinical Presentation}

After an incubation period of 10-15 days, infants develop an abrupt high fever that can reach beyond $40{ }^{\circ} \mathrm{C}$. This may last for $3-5$ days, without other clear physical findings. The fever is followed by an abrupt defervescence that coincides with the development of the exanthem. During the febrile days, the infant can be active and well-appearing. Sometimes they may be irritable. Other clinical manifestations that have 
been reported during the febrile period include inflammation of the tympanic membranes, diarrhea, vomiting, bulging fontanelle, and an enanthem in two thirds of cases referred to as Nagayama spots, which are small red papules located on the soft palate and uvula.

The skin rash that develops after the patient becomes afebrile is macular or maculopapular. It appears first on the trunk and neck and then spreads to the face and extremities. It is usually nonpruritic and lasts for 24-48 h.

\section{Lab Investigations}

Because of the lack of specific physical findings during the febrile phase, many infants undergo laboratory evaluation. Findings may include leukocytosis, leukopenia, atypical lymphocytosis, and thrombocytopenia. Pyuria can be observed, which can be confused with a urinary tract infection (UTI). However, urine culture is negative for bacterial growth.

\section{Complications}

Complications of roseola are uncommon, and most infants recover spontaneously without sequelae. However, they will continue intermittent shedding of the virus from body secretions for life. In individuals with immunocompromising conditions, reactivation of dormant HHV-6 can lead to encephalitis and cause graft-versus-host disease in liver or bone marrow transplant patients.

\section{Treatment and Prevention}

Treatment is supportive and may include antipyretics for the treatment of fever. As the transmission of HHV-6 often involves asymptomatic healthy individuals, prevention is difficult. No vaccine is available.

\section{Erythema Infectiosum (Fifth Disease)}

Erythema infectiosum (EI) is a mild self-limiting disease caused by Parvovirus B19 infection.

\section{Epidemiology}

EI mainly affects school-aged children and usually occurs in epidemics in winter and spring. Males and females are equally affected.

\section{Patient Approach}

\section{Clinical Presentation}

The virus is transmitted via respiratory droplets. After a 1-2-week incubation period, the child starts to have a nonspecific prodromal phase that manifests as fever, headache, sore throat, rhinorrhea, and arthralgia. Two to four days later, facial malar rash appears with circumoral pallor that gives patients the so-called "slappedcheek appearance." Three to five days later a macular skin rash starts to appear on the trunk and extremities that lasts for few days and has a lacy-reticulated appearance as it starts to fade. After its resolution, the patient may experience recurrence of the rash in response to certain stimuli such as stress, exercise, and exposure to heat, a phase which can last for several weeks.

\section{Complications}

EI is mild self-limiting disease that usually resolves without complications in immunocompetent individuals. Aplastic crisis may occur in children with underlying hematologic abnormalities. Arthropathies are estimated to affect $10 \%$ of pediatric patients and up to $60 \%$ of adult patients [13]. 


\section{Treatment and Prevention}

Treatment is largely supportive and symptomatic. Isolation of affected individuals is not necessary as the rash is thought to be autoimmune in nature and the patient is no longer infectious when the exanthem appears.

\section{Laryngotracheobronchitis}

\section{Definition and Background}

Laryngotracheobronchitis, also known as croup, is a common viral infection affecting children under the age of 5 years. It primarily affects children between the age of 6 months and 3 years old. It is uncommonly seen among patients over 6 years of age.

\section{Epidemiology}

Croup affects about $3 \%$ of children per year, and it accounts for about $7 \%$ of hospitalizations in the United States in children younger than 5 years of age. The main causative agent of croup is the parainfluenza virus (paramyxovirus family), primarily types 1 and 2, which cause $75 \%$ of cases. Other viral causes include influenza $A$ and B, measles, adenovirus, and respiratory syncytial virus (RSV) [14]. In some circumstances, superimposed bacterial infections can follow viral croup.

Viruses causing acute infectious croup are spread through either direct inhalation from a cough and/or sneeze, or by contamination of hands from contact with fomites and subsequent touching the mucosa of the eyes, nose, and/or mouth.

\section{Classification}

Croup can be classified as mild, moderate, severe or life-threatening, according to the severity of the presenting symptoms (see Table 1). Hypoxemia is a very serious late sign and indicates life threatening croup.

\section{Patient Approach}

\section{History}

Like most other viral infections, the onset of cough and stridor is usually preceded by coryza and a low grade fever $\left(38-39{ }^{\circ} \mathrm{C}\right)$ that can sometimes exceed $40{ }^{\circ} \mathrm{C}$, and a cough. Within 1-2 days, the characteristic signs of hoarseness, barking cough, and inspiratory stridor develop, often suddenly, along with a variable degree of respiratory distress. Symptoms are perceived as worsening at night, with most emergency room visits occurring between the hours of $10 \mathrm{pm}$ and 4 am. Symptoms typically resolve within 3-7 days but can last up to 2 weeks.

History of barking cough and stridor is usually gradual, with sudden increases in symptoms occurring at night. In cases of sudden onset stridor and cough, there should be consideration of the possibility of foreign body aspiration.

\section{Physical Examination}

Once croup is suspected, a physical examination should take place and should be carried out preferably while the child is calm to minimize work of breathing. The examination should start by inspecting the overall appearance of the child.

Regarding vitals, determining the respiratory rate is important, as is documenting temperature, pulse rate, and oxygenation. It is also essential to assess the hydration status of the patient, especially in infants.

Specific examinations of the respiratory system include observation of the use of accessory muscles for respiration, subcostal and intercostal retractions, and nasal flaring. The physical examination is key in the diagnosis and classification of the severity of croup and its subsequent management.

\section{Lab and Imaging}

Most of cases of croup do not require blood tests or imaging. However, in cases where the history and physical examination is not clear, or when there is a clinical suspicion of other diagnoses, neck or chest X-ray might be required. If lateral neck X-ray is obtained and the classic appearance, "steeple sign" (due to the narrowing of the 
Table 1 Croup severity classification ${ }^{\mathrm{a}}$

\begin{tabular}{l|l|l|l}
\hline Item & Mild & Moderate & Severe \\
\hline $\begin{array}{l}\text { General } \\
\text { behavior }\end{array}$ & Normal & Mild intermittent agitation & Drowsiness or severe agitation \\
$\begin{array}{l}\text { Presence of } \\
\text { stridor }\end{array}$ & $\begin{array}{l}\text { Only with } \\
\text { irritation or } \\
\text { activity }\end{array}$ & Intermittent at rest & Continuous at rest \\
\hline $\begin{array}{l}\text { Signs of } \\
\text { respiratory } \\
\text { distress }\end{array}$ & None & $\begin{array}{l}\text { Mild increase of accessory muscles, nasal } \\
\text { flaring, and increased respiratory rate }\end{array}$ & $\begin{array}{l}\text { Marked use of accessory muscles of } \\
\text { respiration } \\
\text { Increased or decreased respiratory } \\
\text { rate (muscle fatigue) }\end{array}$ \\
\hline Hypoxemia & & $\begin{array}{l}\text { Very late and serious sign indicates } \\
\text { life threatening airway obstruction }\end{array}$ \\
\hline
\end{tabular}

${ }^{\mathrm{a}}$ Adapted from several references and guidelines $[17,18]$

subglottic area) may be seen, which supports the diagnosis of croup.

\section{Differential Diagnosis}

These include serious causes of acute stridor especially epiglottitis, foreign body inhalation, bacterial tracheitis, bronchiolitis, pneumonia, hyperreactive airway disease, or asthma.

\section{Treatment}

A recent Cochrane review concluded that croup score in children with mild to moderate croup does not improve greatly with inhalation of humidified air [15].

Medical treatment of croup depends on the assessment and severity of the case. In all cases parents should be counseled about the course of the disease and the red flags where urgent care should be sought.

In case of mild croup: the child is given oral steroids (one dose of dexamethasone $0.15-0.6 \mathrm{mg} / \mathrm{kg}$ or two doses of prednisolone $1 \mathrm{mg} / \mathrm{kg}$, with the second dose given after $24 \mathrm{~h}$ of the first) and discharged, if patient is tolerating liquids. In the case of moderate croup; the child is given steroids (the same as for mild croup) and monitored for $4 \mathrm{~h}$. If the child improves then she/he can be discharged. If the child does not show improvement or deteriorates then the patient should be managed as severe croup. In severe croup the child should be given oral or IM/IV dexamethasone of $0.6 \mathrm{mg} / \mathrm{kg}$ and be started on epinephrine nebulizers. Epinephrine should be given at the recommended dose of $0.05 \mathrm{~mL}$ per $\mathrm{kg}$ of racemic epinephrine $2.25 \%$ (maximum dose $=0.5 \mathrm{~mL}$ ) or $0.5 \mathrm{~mL} / \mathrm{kg}$ of L-epinephrine 1:1,000 via nebulizer (maximum dose $=5 \mathrm{~mL}$ ). After administration of epinephrine nebulizer, the child should be monitored at least for $4 \mathrm{~h}$, as rebound bronchoconstriction and edema can occur. After $4 \mathrm{~h}$ if the symptoms have resolved and the child has no accessory muscle use or stridor at rest, then the child can be discharged. If there is no or only partial improvement, then the child should be admitted to the hospital for further care. If at any point the child becomes hypoxemic then arrangements should be made for the child to be admitted to the pediatric intensive care unit without delay.

Epinephrine works via adrenergic stimulation, which causes constriction of the precapillary arterioles, thereby decreasing capillary hydrostatic pressure. This leads to fluid resorption from the interstitium and improvement in laryngeal mucosal edema [16].

\section{Epiglottitis}

Acute epiglottis is a life-threatening condition that should be considered when evaluating children with stridor. The prevalence of acute epiglottitis dramatically declined after the introduction of the $H$. influenza vaccination. Epiglottitis usually occurs in children 2-7 years of age, with a peak incidence at 3 years of age. The classical 
presentation is with sudden onset of high fever and the child looks toxic and may be agitated. Respiratory efforts are usually increased with auditable stridor, dyspnea, muffled voice, dysphagia, and drooling. Sitting in a forward leaning (tripod) position with the mouth open and the tongue somewhat protruding might be observed in older children. The classical appearance of the "thumb sign" on lateral neck X-ray can be found in around $95 \%$ of cases [19], but once suspected, emergent referral to a higher level of care and preparation for airway management must be initiated without delay.

\section{Acute Gastroenteritis in Children}

\section{Definition}

Acute gastroenteritis is a clinical syndrome often defined by increased stool frequency (e.g., $\geq 3$ loose or watery stools in $24 \mathrm{~h}$ or a number of loose/watery bowel movements that exceeds the child's usual number of daily bowel movements by two or more), with or without vomiting, fever, or abdominal pain [20].

\section{Epidemiology}

Gastroenteritis is the second leading cause of mortality among children between 1 and 59 months of age [21].

Pathogens causing gastroenteritis can be viral, bacterial, or parasitic; they are usually transmitted via the fecal-oral route. Viruses are the most common pathogens among children younger than 2 years, while bacterial and parasitic infections tend to affect older children and adults.

Rotavirus infection tends to occur in fall and winter. After the introduction of a rotavirus vaccine, norovirus is seen more commonly. Other viral causes of acute gastroenteritis include astrovirus, enteric adenovirus, and sapovirus. In most cases of acute gastroenteritis, diarrhea resolves within 1 week and vomiting within 1-2 days.
Bacterial gastroenteritis can occur following ingestion of poorly cooked meats, eggs, seafood, or unpasteurized milk. Clinically, patients tend to have more pronounced abdominal pain, high fever, and smaller stool volume compared to patients with viral gastroenteritis. In addition, they may have tenesmus and blood or mucus in the stool. Common bacterial causes include Enterotoxigenic E. coli, Enteroinvasive E. coli, Enterohemorrhagic E. coli, Salmonella, Shigella, Campylobacter, and Clostridioides difficile.

\section{Differential Diagnosis}

Gastroenteritis should be differentiated from other causes of diarrhea or vomiting such as systemic infections (e.g., pneumonia, urinary tract infection, meningitis, and otitis media), other viral infections like influenza and measles, diabetic ketoacidosis, and acute abdominal emergencies such as appendicitis and intussusception.

\section{Clinical Evaluation}

\section{History and Physical Examination}

History and physical examination should focus on the presence of symptoms of other causes of diarrhea and vomiting, recent contact with individuals with gastroenteritis, especially in the household or day care settings, food exposures, travelling abroad, or recent treatment with antibiotics. Hydration assessment is vital, caregivers should be asked about oral intake especially in the presence of vomiting, increased thirst, and reduced urine output. A more comprehensive evaluation of the hydration status may be elicited by physical examination (Table 2).

\section{Lab Investigations}

Stool studies (stool analysis, stool culture, and viral antigen detection) are indicated in cases of prolonged diarrhea beyond 7 days, in the presence of blood or mucus in stool, and in immunocompromised patients. Fecal leukocytes are frequently 
Table 2 Clinical features in infants and children with dehydration

\begin{tabular}{l|l|l|l}
\hline Clinical feature & Mild $(3-5 \%)$ & Moderate $(5-10 \%)$ & Severe $(>10 \%)$ \\
\hline General appearance & Restless & Irritable, restless & Lethargic, unconscious \\
\hline Tears & Normal & Normal or reduced & Absent \\
\hline Eyes & Normal & Slightly sunken & Deeply sunken \\
\hline Mucous membrane & Normal or slightly dry & Dry & Parched \\
\hline Fluid intake & Thirsty & Thirsty, drinks eagerly & Drinks poorly \\
\hline Skin turgor & Normal & Reduced (recoils in $<2 \mathrm{~s})$ & Reduced (recoils in $>2 \mathrm{~s})$, tenting \\
\hline Capillary refill time & Normal $(<2 \mathrm{~s})$ & Delayed $(>2 \mathrm{~s})$ & Very delayed $(>3 \mathrm{~s})$ \\
\hline Blood pressure & Normal & Normal to low & Hypotension \\
\hline Pulse rate & Normal & Tachycardia & Tachycardia or bradycardia \\
\hline Respiratory rate & Normal & Increased & Deep \\
\hline Fontanelles & Normal & Depressed & Markedly depressed \\
\hline Urine output & Normal or slightly reduced & Markedly reduced & Absent for several hours
\end{tabular}

present in bacterial gastroenteritis. Electrolytes should be assessed in cases of severe dehydration to guide fluid management. In patients with suspected pseudomembranous colitis, a positive stool test for Clostridioides difficile toxin confirms the diagnosis.

\section{Treatment}

Management of acute gastroenteritis is largely supportive, with fluid management being the cornerstone. The use of antimotility agents in gastroenteritis is not recommended as they can prolong the course of bacterial diarrhea as they delay transit time. The use of adsorbents like smectites, a.k.a. diosmectite (brand names Smecta, Smecdral, Diosecta) can help reduce water loss and therefore can be considered for management of acute gastroenteritis [20]. Diosmectite is available in European countries, Asia, and Africa. Antiemetics are not recommended for routine use in the presence of vomiting as they can have serious adverse effects.

\section{Fluid Management}

Management of dehydration can be accomplished over three phases; deficit replacement, maintenance and ongoing losses replacement. The amount and type of fluids to be given during the deficit replacement phase depends on the degree of dehydration.

\section{Oral Rehydration Therapy}

Oral rehydration therapy (ORT) reduces childhood mortality from diarrheal disease. ORT is composed of water, glucose, and electrolytes. It can be given by parents or caregivers in both home and hospital settings without the need for intravenous access. ORS should be given in small amounts by spoon or syringe $(5 \mathrm{~mL}$ every 1-2 $\mathrm{min})$. The WHO and the UNICEF recommend a reduced-osmolarity formulation of ORT to avoid the risk of hypernatremia [22], with the ideal solution having a low osmolarity (210-250 $\mathrm{mOsmol} / \mathrm{L})$ and a sodium content of $50-60 \mathrm{mmol} / \mathrm{L}$.

\section{Deficit Replacement}

Children manifesting no significant signs of dehydration who are considered to have mild dehydration $(<5 \%)$ do not require deficit replacement. In patients with moderate (5-10\%) dehydration, ORS are administered at a volume of $50-100 \mathrm{~mL} / \mathrm{kg}$ over $4 \mathrm{~h}$. In children with moderate dehydration, who cannot tolerate oral intake, a bolus of IV isotonic saline given as $10 \mathrm{~mL} / \mathrm{kg}$ over 30-60 min can be used, followed by ORS to complete the deficit replacement.

Patients with $>10 \%$ dehydration IV fluids are given initially as rapid infusion of $20-30 \mathrm{~mL} / \mathrm{kg}$ of isotonic saline over $30 \mathrm{~min}$ to restore the circulation, followed by $70 \mathrm{~mL} / \mathrm{kg}$ of isotonic saline over $2.5 \mathrm{~h}$. As soon as the patient can tolerate oral intake, ORT should be initiated in addition to IVF, 
since most isotonic intravenous solutions replace water and $\mathrm{Na}$ but do not replace glucose, $\mathrm{K}$, or other electrolyte losses. Replacement fluids should be continued under supervision until all the initial signs of dehydration are absent and the patient has urinated. This may require more fluids than initially estimated.

\section{Maintenance Fluids and Ongoing Losses}

Once repletion has been completed patients should be started on maintenance fluids given as ORS and feeding should be resumed. In addition, children who manifest no signs of dehydration at presentation can be sent home safely with ORS maintenance treatment. Maintenance fluids are calculated based on patient's weight according to the Holliday-Segar method $(100 \mathrm{~mL} / \mathrm{kg}$ for the initial $10 \mathrm{~kg}$ body weight, $50 \mathrm{~mL} / \mathrm{kg}$ for the second $10 \mathrm{~kg}$ of body weight, and $20 \mathrm{~mL} / \mathrm{kg}$ for the rest of their body weight) given over $24 \mathrm{~h}$. During both the deficit replacement and maintenance phases, ongoing losses by emesis or diarrhea should be estimated as $10 \mathrm{~mL} / \mathrm{kg}$ for each episode of diarrhea and $2 \mathrm{~mL} / \mathrm{kg}$ for each episode of emesis. These losses should be added to the amount of fluids to be given in the next hour.

\section{Nutrition and Zinc Supplements}

Children with acute gastroenteritis should be encouraged to start solid foods as soon as oral intake is tolerated and in infants, breastfeeding or undiluted formula intake continues during the deficit replacement phase as well as during the maintenance phase. During the refeeding process, complex carbohydrates, vegetables, fruits, lean meats, and yogurt are usually tolerated, while fatty foods and foods rich in sugars should be avoided as they can increase diarrhea. The WHO recommends oral zinc sulfate for children under 5 years of age with infectious diarrhea $(10 \mathrm{mg} /$ day for children under 6 months and $20 \mathrm{mg}$ /day for children 6 months to 5 years, each for 10-14 days), to reduce the severity and duration of diarrhea and reduce the incidence of subsequent episodes of diarrhea for several months [23].

\section{Antibiotics}

Antibiotics are not indicated for most children with acute watery diarrhea, except in patients with suspected cholera, in which case macrolides, fluoroquinolones, and tetracyclines are possible options. Azithromycin, ciprofloxacin, and cefixime can be considered empirically in severe cases of bloody diarrhea while awaiting stool culture results. Antibacterial agents should be avoided when enterohemorrhagic $E$. coli infection is clinically suspected to avoid increasing the risk of hemolytic uremic syndrome. Table 3 summarizes antimicrobial agents for common pathogens causing bloody diarrhea, following the result of stool culture.

\section{Probiotics}

Several studies that have been conducted on probiotics in pediatric patients with acute bacterial diarrhea found that probiotics (like Lactobacillus rhamnosus GG, Saccharomyces boulardii, and Lactobacillus reuteri) may be effective in reducing duration and severity of symptoms [24].

\section{Prevention and Vaccination}

Acute gastroenteritis can be prevented by meticulous public and personal hygiene especially in childcare facilities. Thorough cooking of meats and poultry are recommended as well as avoidance of unpasteurized milk. Breastfeeding should be encouraged. Breast milk is rich in antibodies and other factors protective against gastroenteritis. Vaccines to prevent rotavirus and hepatitis $\mathrm{A}$ infections are recommended. Rotavirus vaccine is an orally administered live virus vaccine that is given in two or three doses depending on the specific vaccine administered. 
Table 3 Oral antimicrobial agents for bloody diarrhea in children based on infecting organism

\begin{tabular}{|c|c|c|c|c|c|}
\hline & & Drug & $\begin{array}{l}\text { Dose and } \\
\text { administration }\end{array}$ & Duration & Notes \\
\hline Shigella & & Azithromycin & $\begin{array}{l}12 \mathrm{mg} / \mathrm{kg} \text { day } 1 \\
\text { followed by } \\
6 \mathrm{mg} / \mathrm{kg} \text { daily for } \\
\text { days } 2-5\end{array}$ & 5 days & \\
\hline & & Cefixime & $\begin{array}{l}8 \mathrm{mg} / \mathrm{kg} / \text { day } \mathrm{QD} \\
\text { or BID }\end{array}$ & 5 days & \\
\hline & & TMP-SMX & $\begin{array}{l}8-10 \mathrm{mg} / \mathrm{kg} \\
\text { (based upon TMP } \\
\text { component) BID }\end{array}$ & 5 days & If isolated strain is susceptible \\
\hline Salmonella (no & yphoidal) & TMP-SMX & $8-10 \mathrm{mg} / \mathrm{kg}$ BID & $7-10$ days & $\begin{array}{l}\text { Their use should be preserved } \\
\text { for young infants, infants with } \\
\text { high fever and } \\
\text { immunocompromised children }\end{array}$ \\
\hline & & Cefixime & $\begin{array}{l}8 \mathrm{mg} / \mathrm{kg} / \text { day QD } \\
\text { or BID }\end{array}$ & $7-10$ days & \\
\hline & & Azithromycin & $\begin{array}{l}15 \mathrm{mg} / \mathrm{kg} \text { day } \\
1 \text { followed by } \\
10 \mathrm{mg} / \mathrm{kg} \text { daily } \\
\text { days } 2-5\end{array}$ & 5 days & \\
\hline Campylobacte & & Azithromycin & $\begin{array}{l}15 \mathrm{mg} / \mathrm{kg} \text { day } \\
1 \text { followed by } \\
10 \mathrm{mg} / \mathrm{kg} \text { daily } \\
\text { days } 2-5\end{array}$ & 5 days & $\begin{array}{l}\text { Effective if started in the first } \\
3 \text { days of disease onset }\end{array}$ \\
\hline Entamoeba tro & lozoites & Metronidazole & $\begin{array}{l}35-50 \mathrm{mg} / \mathrm{kg} / \mathrm{day} \\
\text { TID }\end{array}$ & $7-10$ days & \\
\hline Giardia & & Metronidazole & $15 \mathrm{mg} / \mathrm{kg} /$ day TID & 5-7 days & \\
\hline $\begin{array}{l}\text { Clostridioides } \\
\text { Difficile }\end{array}$ & $\begin{array}{l}\text { Mild to } \\
\text { moderate }\end{array}$ & Metronidazole & $\begin{array}{l}30 \mathrm{mg} / \mathrm{kg} / \text { day } \\
\text { QID }\end{array}$ & $7-14$ days & \\
\hline & $\begin{array}{l}\text { Severe } \\
\text { or }\end{array}$ & Vancomycin & $\begin{array}{l}40 \mathrm{mg} / \mathrm{kg} / \mathrm{day} \\
\text { QID }\end{array}$ & 10 days & \\
\hline & recurrent & Fidaxomicin & $200 \mathrm{mg}$ BID & 10 days & For children $>6$ years \\
\hline
\end{tabular}

\section{Kawasaki Disease}

\section{Definition/Background}

Kawasaki disease (KD) is a systemic vasculitis affecting small- and medium-sized blood vessels and it is considered the leading cause of acquired heart disease in industrialized countries [25].

\section{Epidemiology}

The estimated incidence of KD in North America is $\approx 25$ cases per 100,000 children [26]. The highest incidence is reported in Japan where incidence can reach 243.1 per 100,000 population aged $0-4$ years. This disease has a ratio of males to females of $\approx 1.5: 1$ [27].

\section{History and Physical Examination}

Typically, children with KD are less than 5 years old, but older children and rarely adolescents can be affected. KD is characterized by persistent fever for at least 5 days. In the absence of appropriate therapy, fever can continue for 1-3 weeks [28].

Parents might describe redness and painful swelling on the palms and soles of affected children. After 2-3 weeks desquamation of the fingers and toes takes place, which might extend 
to palms and soles, and a couple of months later Beau's lines (deep transverse grooves across the nails) might be noticed [25, 27].

The morphology of rash in KD may vary. While diffuse maculopapular eruption is most common, scarlatiniform rash, erythroderma, or erythema multiforme-like rashes are also seen. Less frequently urticarial rash can occur [26]. An unusually severe form of psoriasis with plaques and pustular features can rarely occur during or after the acute KD illness [29]. Patients also experience bilateral bulbar nonexudative conjunctival injection which usually begins shortly after the onset of fever and often spares the limbus. Anterior uveitis may be observed by slit-lamp examination during the first week of fever.

Signs and symptoms in the lips and oral cavity include erythema, dryness, fissuring, peeling, cracking, and bleeding of the lips; a "strawberry tongue," with erythema and prominent fungiform papillae; and diffuse erythema of the oropharyngeal mucosa.

Cervical lymphadenopathy is the least common clinical feature. Lymph node swelling is usually unilateral, $\geq 1.5 \mathrm{~cm}$ in diameter, and confined to the anterior cervical triangle [30]. In a small subset of patients, lymph node findings may be the most notable and sometimes they are the only initial clinical finding, prompting a clinical diagnosis of bacterial lymphadenitis, and significantly delaying KD diagnosis [30].

There is no specific test for $\mathrm{KD}$. The diagnosis is a clinical one [26].

Classic KD is diagnosed in the presence of fever for at least 5 days (the day of fever onset is taken as the first day of fever) together with at least four of the five following principal clinical features:

1. Erythema and cracking of lips, strawberry tongue, and/or erythema of oral and pharyngeal mucosa

2. Bilateral bulbar conjunctival injection without exudate

3. Rash: maculopapular, diffuse erythroderma, or erythema multiforme-like
4. Erythema and edema of the hands and feet in acute phase and/or periungual desquamation in subacute phase

5. Cervical lymphadenopathy $(\geq 1.5 \mathrm{~cm}$ diameter), usually unilateral

However, patients may not exhibit four or more clinical features at once, rendering diagnosis difficult. For example, some patients may present with fever and meet two or three of the classic criteria. These patients are considered to have incomplete $\mathrm{KD}$ [28].

\section{Laboratory and Imaging}

As mentioned above, the diagnosis of $\mathrm{KD}$ is a clinical one. However, initial laboratory evaluation may be required when the clinical presentation does not meet the full criteria of complete KD and it may include a complete blood count (CBC), electrolyte panel, renal function testing, liver enzymes, albumin, erythrocyte sedimentation rate (ESR), C-reactive protein (CRP), and urinalysis. Abnormal limits include Albumin $3 \mathrm{~g} / \mathrm{dL}$ or less, anemia for age, elevated ALT levels, platelets $>450,000$, WBC count $15,000 / \mathrm{mm}^{3}$ or greater, and sterile pyuria. Three or more positive laboratory criteria are supportive of a diagnosis of KD.

Echocardiography should be performed to evaluate for coronary artery abnormalities or involvement during the acute stage and it should be repeated at 1-2 weeks and then 5-6 weeks after disease onset. Transthoracic echocardiography is the diagnostic imaging modality of choice to screen for coronary aneurysms. MRI and MRA may be used to image peripheral artery aneurysms.

Cardiac stress testing for reversible ischemia is indicated to assess the existence and functional consequences of coronary artery abnormalities in children with Kawasaki disease and coronary aneurysms. 


\section{Treatment}

The goal of therapy in the acute phase of KD is to reduce inflammation and arterial damage and to prevent thrombosis in patients with coronary artery abnormalities. The mainstay of initial treatment for both complete and incomplete $\mathrm{KD}$ is a single high dose of IVIG together with acetylsalicylic acid (ASA). IVIG should be instituted as early as possible within the first 10 days of illness marked by the onset of fever. Referral to specialized care is warranted once $\mathrm{KD}$ is suspected [26, 31].

\section{Medications/Immunizations and Chemoprophylaxis, Referrals, and Counseling}

Current long-term management protocols are calibrated to the degree of coronary artery involvement reflecting the known likelihood of severe long-term cardiac complications. Therefore, patients are managed according to risk category [32].

\section{Patient Education and Activation}

Since affected children are at risk of complications throughout their lives, parents should be educated to help their children adopt a healthy lifestyle and to avoid cardiovascular risk factors, including obesity, high-fat/high-calorie diets, sedentary lifestyle, alcohol use, and tobacco use, to limit their already high cardiac risk.

\section{Prevention}

There are no known preventive measures for Kawasaki disease. Approximately one patient in every hundred cases may develop a recurrence. Parents should be counseled that there is nothing they could have done to prevent the disease.

\section{Pinworms}

\section{Epidemiology}

Pinworm infestation is one of the most common parasitic infections seen by family physicians. The infection is caused by a small, thin, white roundworm called Enterobius vermicularis. Of all age groups, school aged children are most at risk for pinworm infections, particularly those who live in close, crowded conditions [31].

\section{Transmission}

E. vermicularis is transmitted via the fecal oral route. The cycle begins when the gravid adult female worms lay their eggs on the perianal folds. Scratching of the perianal area then leads to autoinfection by transfer of infective eggs to the mouth. Following ingestion, it takes about 1-2 months for the gravid adult female to mature and migrate to the colon where it lays eggs around the anus at night. Each female worm can produce 10,000 or more eggs. Since humans are the only natural host, person-to-person transmission can occur by eating food touched by contaminated hands or by handling contaminated clothes or bed linens or through contact with environmental surfaces that are contaminated with eggs. In addition, eggs may become airborne, inhaled, and swallowed.

\section{Clinical Presentation and Diagnosis}

\section{History and Physical Examination}

Affected children usually present with complaints of anal itching, also known as pruritus ani, which is most severe at nighttime or in the early morning. Pinworms can also cause vulvar symptoms, such as itching. Children with recurrent episodes of vulvar itching, especially at night, should be examined for pinworms. The worm count might get so high that abdominal pain, nausea, and 
vomiting develop. Most patients, however, are asymptomatic. Pinworms have also been linked to appendicitis and Eosinophilic enterocolitis. Adult pinworms may be found in normal and inflamed appendices following surgical removal. Urinary tract infections have also been described in young girls with pinworms.

\section{Laboratory and Imaging}

The female pinworm $(10 \mathrm{~mm})$ can be seen in the perianal region with the naked eye so parents can simply look for the worms in the perianal region $2-3 \mathrm{~h}$ after the child wakes from sleep. Alternative techniques such as the "scotch tape test" and analyzing samples from under the fingernails under a microscope can aid in the diagnosis. The "scotch tape test" involves the use of a transparent tape which is applied to the perianal area to collect possible pinworm eggs around the anus first thing in the morning. If a person is infected, the eggs on the tape will be visible under a microscope. The tape method should be conducted on three consecutive mornings right after the infected person wakes up and before he/she bathes or washes the perianal area $[31,33]$.

\section{Treatment}

It is important to simultaneously treat the entire household for pinworms when a decision is made to treat. Anthelmintics, such as mebendazole (100 mg PO as a single dose), pyrantel pamoate (11 mg (base)/kg PO not to exceed $1 \mathrm{~g} /$ dose), and albendazole $(400 \mathrm{mg} \mathrm{PO} \times 1)$, are active against Enterobius vermicularis. Any of these drugs are given as a single initial dose, and then another single dose of the same drug is given 2 weeks later to prevent re-infection by adult worms that hatch from eggs not killed by the first treatment $[31,33]$.

\section{Prevention}

Children should be encouraged to wash their hands with soap and warm water after using the toilet and bathe every morning to help reduce the number of eggs on the skin. In institutions, day care centers, and schools, control of pinworm infections can be difficult, but mass drug administration during an outbreak can be successful [31].

\section{References}

1. Thomas K. Education and expectations for patients with viral upper respiratory infections (2019). Family Medicine Clerkship Student Projects. 467. https:// scholarworks.uvm.edu/fmclerk/467.

2. Alsuhaibani MA, AlKheder RS, Alwanin JO, Alharbi MM, Alrasheedi MS, Almousa RF. Parents awareness toward antibiotics use in upper respiratory tract infection in children in Al-Qassim region, Saudi Arabia. J Fam Med Prim Care. 2019;8(2):583.

3. Jain N, Lodha R, Kabra S. Upper respiratory tract infections. Indian J Pediatr. 2001;68(12):1135-8.

4. Singh M, Singh M, Jaiswal N, Chauhan A. Heated, humidified air for the common cold. Cochrane Database Syst Rev. 2017; (8):CD001728.

5. DeGeorge KC, Ring DJ, Dalrymple SN. Treatment of the common cold. Am Fam Physician. 2019;100(5): 281-9.

6. Hemilä H, Haukka J, Alho M, Vahtera J, Kivimäki M. Zinc acetate lozenges for the treatment of the common cold: a randomised controlled trial. BMJ Open. 2020;10(1):e031662.

7. Rosano A, Punzo O, Pezzotti P. Childhood flu vaccination an opportunity to reduce the burden of disease due to influenza epidemics. J Vaccines Immunol Immunopathol. 2019;4:146.

8. Callister LC. Global measles outbreak. MCN Am J Matern Child Nurs. 2019;44(4):237.

9. World Health Organization. Response to measles outbreaks in measles mortality reduction settings. Geneva: World Health Organization; 2009.

10. Zuckerman AJ. Principles and practice of clinical virology. Chichester: Wiley; 2009.

11. Straus SE, Ostrove JM, Inchauspé G, Felser JM, Freifeld A, Croen KD, et al. Varicella-zoster virus infections: biology, natural history, treatment, and prevention. Ann Intern Med. 1988;108(2):221-37.

12. Zerr DM, Meier AS, Selke SS, Frenkel LM, Huang M-L, Wald A, et al. A population-based study of primary human herpesvirus 6 infection. N Engl J Med. 2005;352(8):768-76.

13. Dobec M, Kaeppeli F, Cassinotti P, Satz N. Persistent parvovirus B19 infection and arthralgia in a patient mistakenly treated for Lyme disease. J Clin Virol. 2008;43(2):226-9.

14. Aronson SS, Shope TR. Managing infectious diseases in child care and schools: a quick reference guide. Elk Grove Village: American Academy of Pediatrics; 2016. 
15. Moore M, Little P. Humidified air inhalation for treating croup: a systematic review and meta-analysis. Fam Pract. 2007;24(4):295-301.

16. Bjornson C, Russell K, Vandermeer B, Klassen TP, Johnson DW. Nebulized epinephrine for croup in children. Cochrane Database Syst Rev. 2013; (10):CD006619. PubMed PMID: 24114291. Epub 2013/10/12. eng.

17. Smith DK, McDermott AJ, Sullivan JF. Croup: diagnosis and management. Am Fam Physician. 2018;97(9):575-80. PubMed PMID: 29763253. Epub 2018/05/16. eng.

18. Royal Children's Hospital. Clinical practice guidelines. Croup. Melbourne: Royal Children's Hospital; 2019.

19. Pradhananga RB, Adhikari P, Sinha BK, Thapa N. Prevalence of Acute Epiglottitis and its Association with Pulmonary Tuberculosis in Adults in a Tertiary Care Hospital of Nepal. Int. Arch. Otorhinolaryngol. 2008;12(4):494-497.

20. Guarino A, Ashkenazi S, Gendrel D, Vecchio AL, Shamir R, Szajewska H. European Society for Pediatric Gastroenterology, Hepatology, and Nutrition/European Society for Pediatric Infectious Diseases evidence-based guidelines for the management of acute gastroenteritis in children in Europe: update 2014. J Pediatr Gastroenterol Nutr. 2014; 59(1):132-52.

21. MCEE, W. MCEE-WHO methods and data sources for child causes of death 2000-2015. World Health Organization 2016.

22. World Health Organization. Reduced osmolarity: oral rehydration salts (ORS) formulation: a report from a meeting of experts jointly organised by UNICEF and WHO: UNICEF house, New York, USA, 18 July 2001. No. WHO/FCH/CAH/01.22. World Health Organization, 2002.

23. Liberato SC, Singh G, Mulholland K. Zinc supplementation in young children: a review of the literature focusing on diarrhoea prevention and treatment. Clin Nutr. 2015;34(2):181-8.
24. Szajewska H, Guarino A, Hojsak I, Indrio F, Kolacek S, Shamir R, Vandenplas Y, Weizman Z. Use of probiotics for management of acute gastroenteritis: a position paper by the ESPGHAN Working Group for Probiotics and Prebiotics. J Pediatr Gastroenterol Nutr. 2014;58(4):531-9.

25. Phuong LK, Chen KY, Burgner DP, et al. What paediatricians need to know about the updated 2017 American Heart Association Kawasaki disease guideline. Arch Dis Child. 2020;105:10-2.

26. McCrindle BW, Rowley AH, Newburger JW, Burns JC, Bolger AF, Gewitz M, et al. Diagnosis, treatment, and long-term management of Kawasaki disease: a scientific statement for health professionals from the American Heart Association. Circulation. 2017;135(17):e927-99.

27. Makino N, Nakamura Y, Yashiro M, Ae R, Tsuboi S, Aoyama Y, et al. Descriptive epidemiology of Kawasaki disease in Japan, 2011-2012: from the results of the 22nd nationwide survey. J Epidemiol. 2015;25:239. https://doi.org/10.2188/jea.JE20140089.

28. Singh S, Vignesh P, Burgner D. The epidemiology of Kawasaki disease: a global update. Arch Dis Child. 2015;100(11):1084-8.

29. Eberhard BA, Sundel RP, Newburger JW, Baker A, Fuhlbrigge RC, Burns JC, et al. Psoriatic eruption in Kawasaki disease. J Pediatr. 2000;137(4):578-80.

30. Kanegaye JT, Van Cott E, Tremoulet AH, Salgado A, Shimizu C, Kruk P, et al. Lymph-node-first presentation of Kawasaki disease compared with bacterial cervical adenitis and typical Kawasaki disease. J Pediatr. 2013;162(6):1259-63.e2.

31. Van Weyenberg S, De Boer N. Enterobiasis vermicularis. Video J Encycl GI Endosc. 2013;1(2): 359-60.

32. Manlhiot C, Niedra E, McCrindle BW. Long-term management of Kawasaki disease: implications for the adult patient. Pediatr Neonatol. 2013;54(1):12-21.

33. Huh S. Status of common parasitic diseases in Korea in 2019. J Korean Med Assoc. 2019;62(8):437-56. 